Тромбоз воротной вены (ТВВ) развивается вследствие воздействия локальных (воспалительные заболевания органов брюшной полости, повреждения вены), а также системных фракторов (наследственные и приобретенные тромбофилии). В ряде случаев диагностика ТВВ сопряжена с некоторыми сложностями. Необходимая продолжительность антикоагулянтной терапии до сих пор окончательно не установлена. $B$ статье приведен случай клинического наблюдения пациентки, находившейся на лечении в отделении гематологии с хроническим миелопролиферативным заболеванием, осложнившимся развитием ТВВ. На данном примере показано, что проведение специфрической терапии, включающей антикоагулянтную терапию и назначение цитостатиков, - важнейшая часть лечебного процесса, способствует существенному снижению риска рецидивов тромбозов. Применение комплексного этиопатогенетического подхода к лечению ТВВ на фоне тромбофилии значительно улучшает результаты.

Ключевые слова: тромбоз воротной вены, портальная гипертензия, антикоагулянтная терапия, хроническое миелопролиферативное заболевание.

Для цитирования: Зуховицкая, Е. В. Тромбоз воротной вены: трудности диагностики (случай из практики) / Е. В. Зуховицкая, Э. В. Могилевец, Н. Ф. Василевская // Гепатология и Гастроэнтерология. 2019. Т. 3, № 1. С. 109-112. https://doi.org/10.25298/2616-5546-2019-3-1-109-112

\title{
PORTAL VEIN THROMBOSIS: DIAGNOSTIC DIFFICULTIES (CASE REPORT)
}

${ }^{1}$ E. V. Zuchovitskaya , ${ }^{1} E$. V. Mahiliavets, ${ }^{2}$ N. F. Vasilevskaya ${ }^{1}$ Educational Institution «Grodno State Medical University», Grodno, Belarus ${ }^{2}$ Grodno Regional Clinical Hospital, Grodno, Belarus

Portal vein thrombosis (PVT) results from local factors (abdominal inflammatory diseases, vein injuries) as well as systemic ones (hereditary and acquired thrombophilia). In some cases, the diagnostics of PVT is associated with some difficulties. The necessary duration of anticoagulation therapy hasn't been fully established yet. The article presents a case of clinical follow-up of the patient being treated in the hematology department for chronic myeloproliferative disease, aggravated by the development of PVT. This case shows that specific therapy, including anticoagulation therapy and administration of cytostatic drugs is the most important part of the management and significantly reduces the risk of thrombosis recurrence. The use of complex etiopathogenetic approach to the treatment of PVT aggravated by thrombophilia significantly improves the outcome.

Key words: portal vein thrombosis, portal hypertension, anticoagulation therapy, chronic myeloproliferative disorders

For citation: Zuchovitskaya EV, Mahiliavets EV, Vasilevskaya NF. Portal vein thrombosis: diagnostic difficulties(case from practice). Hepatology and Gastroenterology. 2019;3(1):109-112. https://doi.org/10.25298/2616-5546-2019-3-1-109-112

\section{Введение}

Тромбоз воротной вены (ТВВ) - это обструкция внепеченочной ее части с вовлечением внутрипеченочных ветвей и притоков, или без него. Характеризуется проявлениями острого тромбоза или развитием портальной гипертензии (ПГ), формированием так называемой «портальной каверномы» - последствиями обструкции воротной вены (BВ) [1]. Как известно, ВВ образуется путем слияния селезеночной и верхней брыжеечной вен. Тромб может сформироваться в интрапеченочной части сосуда, что встречается при раке и циррозе печени (ЦП), с последующим распространением процесса на внепеченочную его часть. Тромбоз может возникнуть в селезеночной вене на фоне воспалительного процесса в брюшной полости (чаще хронического панкреатита) и распространиться на ВВ. Однако чаще всего местом тромбоза становится ВВ в месте слияния двух вен.

Распространенность ТВВ в общей популяции в целом колеблется от 1-2 на 100000 населения, однако в определенных группах частота встречаемости его намного выше. Так, распространенность ТВВ у пациентов с компенсированными заболеваниями печени составляет, по разным данным, от 0,6 до 16\%. В популяции пациентов, ожидающих трансплантации печени, данная патология встречается в среднем от 5 до $28 \%$ [2]. У $35 \%$ пациентов с гепатоцеллюлярной карциномой, развившейся на фоне ЦП, также выявляется ТВВ. По результатам 26000 вскры- 
тий, выполненных в Швеции в 1970-1988 гг., распространенность ТВВ в общей популяции составила 1\%. При этом на долю ЦП пришлось $28 \%$. Наиболее частой причиной тромбоза стало злокачественное поражение печени (первичное - 23\%, вторичное - 44\%). В 10\% случаев ТВВ был вызван инфекционным и воспалительным заболеванием органов брюшной полости, в $3 \%$ - миелопролиферативной болезнью. Интересен тот фракт, что в 14\% случаев причины тромбоза не установлены [3].

Этиологические фракторы ТВВ принято разделять на системные и локальные. Группа локальных фракторов включает разные воспалительные процессы органов брюшной полости (панкреатит, холецистит, холангит, воспалительные заболевания кишечника), а также повреждение ВВ (в том числе и ятрогенное) [4]. Исследование с участием 102 пациентов с нецирротическим ТВВ в отсутствие злокачественных новообразований показало, что доля локальных факторов в этиологической структуре тромбоза составляет до $21 \%$. При этом острый панкреатит - наиболее частая причина ТВВ, на втором месте по частоте в рамках данного исследования - холецистит/ холангит и абсцесс печени [5]. К системным фракторам относятся главным образом наследственные и приобретенные тромбофилии. При этом среди приобретенных системных тромбофилий первое место занимают хронические миелопролиферативные заболевания (ХМПЗ), составляя в данной группе от 35 до 55\% [6]. В недавнем исследовании показано, что первым проявлением ХМПЗ в 70\% наблюдений (у 31 из 44 пациентов) является ТВВ. Мета-анализ показал, что средняя распространенность ХМПЗ у этой категории пациентов составляет 31,5\% (95\% ДИ 25,1-38,8\%), в то время как мутация JAK2 выявляется в 27,7\% (95\% ДИ 20,8-35,8\%) [7]. С другой стороны, среди пациентов с неопухолевым нецирротическим тромбозом значение отношения шансов (OR) для таких факторов, как прием оральных контрацептивов, наличие мутаций гена протромбина, фрактора V Лейдена, недостаточности протеина $\mathrm{C}$, протеина $\mathrm{S}$ и антитромбина III составило, соответственно, 50; 7; 3,5; 5; 3 [8]. Мета-анализ частоты развития ТВВ на фоне тромбофилий показал, что частота выявления дефицита АТ III составляет 3,9\%, недостаточности протеина С - 5,6\%, недостаточности протеина S - 2,6\%, мутация фрактора V Leiden - в 3-6\%, антифосфолипидные антитела выявлены у 18-25\% пациентов. К другим протромботическим состояниям, которые приводят к развитию ТВВ, относят пароксизмальную ночную гемоглобинурию, антифосфолипидный синдром, гипергомоцистеинемию. По данным ряда авторов, у 28-62\% пациентов выявляется несколько протромботических состояний [9].
Цель антикоагулянтной терапии у рассматриваемой категории пациентов - уменьшение симптомов ТВВ, предотвращение распространения области тромбоза по системе ВВ и лечение развившихся осложнений (мезентериальной ишемии, портальной гипертензии). Систематические обзоры показывают, что до 83,3\% случаев ТВВ не реканализуются при отсутствии антикоагулянтной терапии. В оставшихся 16,7\% реканализация происходит, как правило, после перенесенного острого панкреатита [10]. Вероятность реканализации составляет от $69 \%$ и выше в случае начала антикоагулянтной терапии в течение первой недели, ее уровень снижается до 25\% при начале лечения в течение второй недели. Необходимая продолжительность антикоагулянтной терапии до сих пор окончательно не установлена. Известно, что реканализация наступает в течение 4-6 месяцев после начала лечения; таким образом, длительность данного вида терапии у этой категории пациентов должна быть не менее 6 месяцев. Более длительная терапия может быть рекомендована пациентам с установленными протромботическими расстройствами, рецидивами тромбозов либо при выявлении семейного анамнеза венозных тромбозов. Раннее назначение антикоагулянтной терапии при тромбозе брыжеечной и воротной вены позволяет минимизировать риск развития и выраженность серьезных осложнений, в частности перитонита, возникающих вследствие мезентериальной ишемии, а также значительно снизить риск осложнений, связанных с формирующимися варикозно-расширенными венами пищевода.

Наиболее противоречивым и сложным остается вопрос о тактике лечения пациентов с ТВВ при наличии ЦП. В последнее время все больше данных говорят в пользу «протромботического дисбаланса», развивающегося при ЦП (в противовес традиционным представлениям о печеночной коагулопатии). Развитию ТВВ способствуют также снижение активности тромбомодулина (мощный антикоагулянт, активатор белка С), увеличение уровня прокоагулянтного фрактора VIII и фрактора фон Виллебрандта в плазме, неэфффективный фибринолизис вследствие снижения уровня плазминогена и повышения уровня ингибитора активатора плазминогена. Активация процессов коагуляции способствует процессу фиброгенеза. Вместе с тем в экспериментальных исследованиях показано, что антикоагулянтная терапия при хронических заболеваниях печени способна ингибировать процессы фриброгенеза [11].

Цель исследования - демонстрация особенностей диагностики и дифференциальной диагностики ТВВ на примере клинического случая. 


\section{Материалы и методы}

Данные клинического наблюдения пациентки Б., 36 лет, находившейся на лечении в отделении гематологии УЗ «Гродненская областная клиническая больница» в октябре 2017 г.

\section{Результаты и обсуждение}

Ведущим клиническим синдромом у пациентки были умеренные ноющие боли в эпигастрии, правом подреберье, чувство тяжести в правом подреберье, выраженная слабость. Из анамнеза заболевания известно, что с марта 2014 г. она наблюдалась в связи с JAK 2+ хроническим миелопролиферативным заболеванием (эссенциальная тромбоцитемия, подтвержденная гистологически после выполнения трепанобиопсии повздошной кости), получала амбулаторно гидроксикарбамид. На момент поступления в общем анализе крови выявлялся только тромбоцитоз $980 \times 10^{12} / л$. Изучение лабораторных показателей функций печени свидетельствовало об отсутствии отклонений, маркеры вирусных гепатитов также не обнаружены. В связи с этим ранее была выполнена ФГДС (заключение: хронический гастрит). При ультразвуковом исследовании органов брюшной полости: контуры печени ровные, размеры нормальные, эхогенность повышена, очаговые изменения отсутствуют; селезенка: размеры увеличенные, 29,1×15,8 см; эхоструктура обычная, очаговые изменения отсутствуют. Для уточнения диагноза проведена ультразвуковая допплерография висцеральных сосудов, позволившая выявить в воротной вене и дистальном сегменте селезеночной и верхней брыжеечной вен гипоэхогенные гетерогенные тромбомассы, кровоток не регистрировался. Это позволило заподозрить ТВВ с развитием подпеченочной портальной гипертензии. В связи с этим, а также для исключения паранеопластического характера ТВВ и ее ветвей пациентке проведена мультиспиральная компьютерная томография (МСКТ) органов брюшной полости с внутривенным введением контрастного вещества. Картина МСКТ показала признаки портальной гипертензии с картиной тромбоза и кавернозной трансформацией ВB с распространением на внутрипеченочные и селезеночную вены, наличие портальной билиопатии, а также спленомегалии. Для исключения венозных тромбоэмболических осложнений другой локализации, в том числе вен нижних конечностей, проведено дуплексное сканирование. Эхо-признаков патологии магистральных вен обеих нижних конечностей, в том числе тромбофлебита и флеботромбоза, в доступных визуализации сегментах венозного русла на момент исследования не выявлено.

При оценке коагулограммы определялось увеличение D-димера до 1,98 мкг/мл. Для ис- ключения врожденной тромбофилии помимо оценки уровня антитромбина III, который был в пределах референсных значений, оценили концентрацию других естественных ингибиторов свертывания: протеина С - 80,0\%, концентрация протеина S - 61,0\%, что также соответствовало референсным границам. Кроме того, проведен анализ полиморфизмов генов факторов свертывания крови методом ПЦР, при этом мутации фактора V (Leiden), протромбина G20210A не выявлены. Повышение уровня антител к фосфатидилинозитолу, фосфатидилсерину, а также к кардиолипину IgG и IgM в среднем титре и волчаночного антикоагулянта 1,8 у. е. (норма <1.2 у. е.) позволило сформулировать диагноз: Хроническое миелопролиферативное заболевание (JAK-2+). Эссенциальная тромбоцитемия. Высокий прогностический риск по шкале IPSET. Тромбоз воротной, селезеночной вен. Кавернозная трансформация ствола и ветвей воротной вены. Внепеченочная портальная гипертензия. Спленомегалия. Антифосфолипидный синдром: двойная позитивность. Высокий риск тромбоэмболических осложнений.

Учитывая сложный генез тромботических осложнений, пациентке рекомендована циторедуктивная терапия гидроксимочевиной: 500 мг 3 раза в день, антикоагулянтная терапия клексаном: 6000 анти-Ха ЕД×2 раза в сутки в течение месяца с последующим переходом на 4000 анти-Ха ЕДхраза в сутки подкожно в течение не менее 6 месяцев. Рекомендовано выполнение ФГДС через 3, 6 и 12 месяцев и УЗДГ в эти же сроки.

ФГДС через 6 месяцев выявила варикозно-расширенные вены (ВРВ) пищевода II степени, признаков угрозы кровотечения нет. По данным УЗДГ и МСКТ брюшной полости, при динамической оценке состояния сосудов портальной системы признаков рецидива/распространения тромбоза не отмечено, по сравнению с первичным обследованием - состояние без динамики, признаков реканализации нет. Учитывая отсутствие угрозы кровотечения из ВРВ пищевода и желудка, а также развившийся портальный тромбоз на фоне комбинированной тромбофилии, антикоагулянтная терапия продолжена на срок до года, после чего пациентка переведена на пероральный прием антикоагулянта - ксарелто, 10 мг в сутки. Указанная терапия проводится и в настоящее время.

\section{Выводы}

Таким образом, сочетание наследственных и приобретенных фрорм тромбофилии - основные факторы риска тромбоза в сосудах системы ВВ. Проведение специфической терапии, включающей антикоагулянтную терапию и назачение цитостатиков, как в нашем случае, - важней- 
шая часть лечебного процесса, способствующая существенному снижению риска рецидивов тромбозов.

Всем пациентам с абдоминальным синдромом в рамках диагностического обследования необходимо проведение УЗДГ портальной системы, «золотого стандарта» диагностики ТВВ. Пациентам с ТВВ необходимо проводить обследование на наследственные и приобретенные тромбофилии. При выявлении тромбофилических состояний обязательным признано проведение антикоагулянтной терапии неопределенно долгий срок, а при выявлении ХМПЗ - сочетание ее с циторедуктивной терапией проводимой совместно со специалистами-гематологами. Применение комплексного этиопатогенетического подхода к лечению ТВВ на фоне тромбофилии значительно улучшает его результаты.

\section{Referenses}

1. de Franchis R, Baveno VF. Revising consensus in portal hypertension: Report of the Baveno V consensus workshop on methodology of diagnosis and therapy in portal hypertension. Journal of Hepatology. 2010;53(4):762-768 doi: 10.1016/j.jhep.2010.06.004

2. Gaiani S, Bolondi L, Li BS, Zironi G, Siringo S, Barbara L. Prevalence of spontaneous hepatofugal portal flow in liver cirrhosis. Clinical and endoscopic correlation in 228 patients. Gastroenterology. 1991;100(1):160-167.

3. Amitrano L, Guardascione MA, Brancaccio V, Margaglione M, Manguso F, lannaccone L, Grandone E, Balzano A. Risk factors and clinical presentation of portal vein thrombosis in patients with liver cirrhosis. Journal of Hepatology. 2006;40(5):736-741. doi: 10.1016/j.jhep.2004.01.001.

4. Primignani M, Martinelli I, Bucciarelli P, Battaglioli T, Reat R, Fabris F, Dell'era A, Pappalardo E, Mannucci PM. Risk factors for thrombophilia in extrahepatic portal vein obstruction. Hepatology. 2005;41(3):603-608. doi: 10.1002/ hep.20591.

5. Pleassier A, Murad SD, Hernandez-Guerra M. A prospective multicentric follow-up study on 105 patients with acute portal vein thrombosis 249 (PVT): results from the European Network for Vascular Disorders of the Liver (ENVIE). Hepatology. 2007;46(Suppl 1):310A.

6. Smalberg JH, Arends LR, Valla DC, Kiladjian JJ, Janssen $\mathrm{HL}$, Leebeek FW. Myeloproliferative neoplasms in BuddChiari syndrome and portal vein thrombosis: a metaanalysis. Blood. 2012;120(25):4921-4928. doi: 10.1182/ blood-2011-09-376517.
7. HoekstraJ,BresserEL,Smalberg JH,SpaanderMC, Leebeek FW, Janssen HL. Long-term follow-up of patients with portal vein thrombosis and myeloproliferative neoplasms. Journal of Thrombosis and Haemostasis. 2011;9(11):2208-2214. doi: 10.1111/j.1538-7836.2011.04484.x.

8. D'Amico M, Sammarco P, Pasta L. Thrombophilic genetic factors PAI-1, MTHFRC677T, V Leiden 506Q, and prothrombin $20210 \mathrm{~A}$ in noncirrhotic portal vein thrombosis and Budd-Chiari syndrome in a caucasian population. International Journal of Vascular Medicine. 2013:2013:717480 doi: 10.1155/2013/717480.

9. Qi X, De Stefano V, Wang J, Bai M, Yang Z, Han G, Fan D. Prevalence of inherited antithrombin, protein $C$, and protein $S$ deficiencies in portal vein system thrombosis and BuddChiari syndrome: a systematic review and meta-analysis of observational studies. Journal of Gastroenterology and Hepatology. 2013;28(3):432-442. doi: 10.1111/jgh.12085.

10. Hall TC, Garcea G, Metcalfe M, Bilku D, Dennison AR. Management of acute non-cirrhotic non malignant portal vein thrombosis: a systematic. World Journal of Surgery. 2011;35(11):2510-2520. doi: 10.1007/s00268-011-1198-0.

11. Dolovich LR, Ginsberg JS, Douketis JD, Holbrook AM, Cheah G. A meta-analysis comparing low-molecular wt heparin with unfractionated heparin in treatment of venous thrombolism examining some unanswered questions regarding location of treatment product use and dosing frequency. Archives of Internal Medicine. 2000;160(2):181188. 